
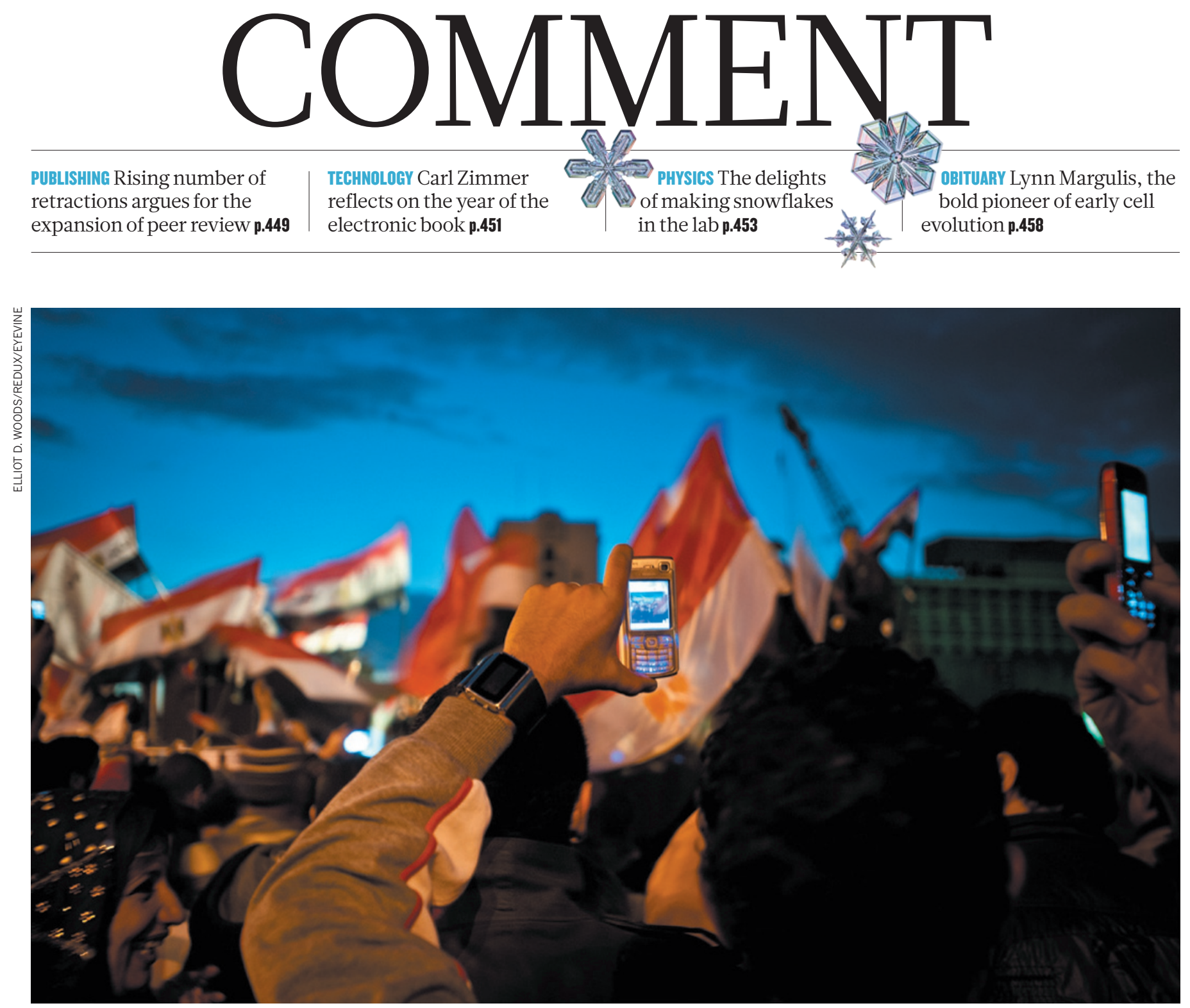

The mass protests in Egypt this year were dubbed a 'Twitter revolution' because of the way they were broadcast around the world through social media.

\title{
The new history
}

The past year has shown how prone a highly networked society is to abrupt change. The future of our complex world, says Philip Ball, depends on becoming resilient to shocks.

$\mathrm{I}$

n the 1990s, political scientist Francis Fukuyama, now at Stanford University in California, predicted that the world was approaching the "end of history" ${ }^{1}$. Like many smart ideas that prove to be wrong, Fukuyama's thesis was illuminating precisely because of its errors. Events of this year help to reveal why: they were shaped by the unprecedented complexity of today's sociopolitical systems.

After the Soviet Union collapsed, Fukuyama argued that liberal democracy would be the logical and stable end point of civilization. Yet this prospect looks more remote today than it did at the end of the twentieth century. Protest movements in the fallout from the financial crisis have legitimately challenged the economic system on which recent liberal democracies have been based. The grave debt crisis in Greece has prompted questions over the usefulness of democracy's ultimate tool, the national referendum, and Italy's economic woes have prompted the appointment of a non-elected prime minister. The political situations in Russia and Turkey suggest that democratization is not inexorable, and North Africa and the Middle East show that it can even inflame conflict. Meanwhile, China continues to show that aggressive capitalism depends on neither liberalism nor democracy. As a 2008 report from the US National Intelligence Council admits, "the Western model of economic liberalism, democracy, and secularism, which many assumed to be inevitable, may lose its luster"2.

The real shortcoming behind Fukuyama's thesis, however, is not his faith in the ascendance of democracy, but his assumption that history is gradualist: that tomorrow will not differ much from today. Instead, the common talk among political analysts now is of discontinuous change ${ }^{3}$. Discontinuities have 
always been with us, in the shape of wars and economic crises, for example. But today, sudden disruptive events don't just happen against a slowly evolving social backdrop they are woven into the fabric of global affairs.

Take the terrorist attack on the World Trade Center's twin towers in New York in 2001. Many said that this proved Fukuyama wrong - but ten years later, we can see more clearly in what way this was so. It was not simply that the attack was a significant historical event - Fukuyama never claimed that those would cease. Rather, it was a harbinger of a new world order, which the subsequent 'war on terror' failed catastrophically to acknowledge in its attempt to establish conventional battlegrounds in Afghanistan and Iraq. Not only were those wars in no sense 'won', the conflicts were barely wars at all. Armed conflict is no longer corralled from peacetime by national declarations and treaties. It is now a diffuse, nebulous affair: a network of insurgents, militias, terrorist cells, suicide bombers and overlapping and sometimes competing 'enemy' organizations. We have had to say farewell to war and peace.

\section{INTERNAL FEEDBACK}

The nature of discontinuous change is often misunderstood. It is sometimes said - this is literally how traditional economists defend their failure to predict the ongoing financial and national-debt crises - that no one can be expected to foresee such radical departures from the quotidian. They emerge, like a hijacked aircraft, out of a clear blue sky. Yet social and political discontinuities are rarely, if ever, random in that sense, even if their immediate triggers have a certain arbitrary character. Rather, they are abrupt in the same way, and for the same reasons, that phase transitions are abrupt in physics. In complex systems, including social ones, discontinuities don't reflect profound changes in the governing forces; they derive from the interactions and feedbacks between the component parts. Discontinuities are therefore precisely what you would expect if you consider today's societies from a complex-systems perspective.

Experience with natural and technological complex systems teaches us that highly connected networks of strong interactions, such as power grids, food webs and computer networks, have a propensity for catastrophic failure and systemic rupture ${ }^{4}$ - in short, for discontinuous change. So it should come as no surprise that today's highly networked, interconnected world is prone to abrupt changes in course.

This phenomenon can be discerned in the revolts in Tunisia and Egypt, dubbed Twitter revolutions because of the way that unrest and news of demonstrations were spread through social networks. Although saying that Twitter caused the revolts is an over-simplification, the networking clearly enabled a random

event to trigger a major one. The Tunisian revolt was set in motion by the self-immolation of a street vendor, Mohamed Bouazizi, in Sidi Bouzid, in protest at harsh treatment by officials. Three months earlier, a similar thing had happened in the city of Monastir - but few people knew about it because it was not publicized on Facebook.

It was surely not without reason that both the Tunisian and the Egyptian authorities shut down Twitter and Facebook. The issue is not so much that these media 'caused' the revolutions, but that they - and their concomitant potential for mobilizing the young and educated - can alter the way things happen in North Africa, the Middle East and beyond. The same tools are now vital to the 'Occupy' protests that are disrupting complacent financial districts worldwide, from New York to

\section{"Social discontinuities are abrupt in the same way, and for the same reasons, that phase transitions are abrupt in physics."} Taipei, drawing attention to issues of social and economic inequality.

Social media seem also to have the potential to facilitate qualitatively new collective behaviours, such as the riots during the summer in the United Kingdom. These brief, destructive paroxysms are still an enigma. Unlike previous riots, they were confined neither to particular demographic subsets nor to areas of serious social deprivation. They had no obvious agenda, not even a release of suppressed communal fury - although they must surely have been linked to post-financial-crash austerity policies. Interaction and feedback, not pre-meditation, seem to lie at their core.

\section{WITHSTANDING SHOCKS}

What these events really point to is the profound effect of globalization. They show how deep and dense the interdependence of economies, cultures and institutions has become, in large part thanks to information and communication technologies. And with this transformation come new, spontaneous modes of social and political organization, from terrorist and protest networks to online consumerism, that are especially prone to discontinuous change. Nothing that fails to take this new interconnectedness into account will work: not the economy, not policing, not democracy.

Such extreme interdependence makes it hard to pinpoint, or even to meaningfully define, the causes of major events. The US subprime-mortgage problem caused the financial collapse only in the way that Bouazizi's selfimmolation caused the Arab Spring - something else could equally have set the events in motion. The real vulnerabilities were systemic: webs of dependence that had become destabilized by, say, runaway profits in the US banking industry, or rising food prices in North Africa. This means that potential solutions must lie within such webs too.

Complex systems can rarely, if ever, be controlled by top-down measures. They must be managed instead by guiding the trajectories from the bottom up ${ }^{5}$. In a simple example, traffic lights tend to direct flows more efficiently if they are given adaptive autonomy and allowed to self-organize their switching, rather than following a rigid, supposedly optimal sequence ${ }^{6}$. The Internet can survive random server failures without a disruption to service precisely because no one designed it - it grew its own adaptive topology.

This does not imply that political interventions are doomed to fail, just that they must take forms different from those commonly used today. "Complex systems cannot be steered like a bus," says Dirk Helbing of the Swiss Federal Institute of Technology (ETH) in Zurich, a specialist on the understanding and management of complex social systems. "Attempts to control the systems from the top down may be strong enough to disturb its intrinsic self-organization but not strong enough to re-establish order. The result would be chaos and inefficiency."

But these systems are still manageable, Helbing insists - not by imposing structures but by creating the transactional rules needed to allow the system to find its own stable organization. Healthy financial markets can't be imposed by central management, for example: they must be grown by finding rules that promote systemic robustness.

That's why theories or ideologies tend to be less effective than scenario modelling at predicting or averting crises. It is why problems need to be considered at several hierarchical levels, probably with multiple, overlapping models. And it is why solutions must have scope for adaptation and flexibility.

Cascading crises and discontinuous changes may be unpredictable, but the connections and vulnerabilities that permit them are not. Planning for the future, then, might not be so much a matter of foreseeing what could go wrong as of making our systems and institutions robust enough to withstand a variety of shocks. This is how the new history will work.

Philip Ball is a writer based in London. e-mail:p.ball@btinternet.com

1. Fukuyama, F. The End of History and the Last Man (Free Press, 1992).

2. National Intelligence Council Global Trends 2025 : A Transformed World (US Government Printing Office, 2008).

3. Handy, C. The Age of Unreason (Harvard Business School Press, 1990).

4. Vespignani, A. Nature 464, 984-985 (2010)

5. Helbing, D. (ed.) Managing Complexity: Insights, Concepts, Applications (Springer, 2008).

6. Lämmer, S. \& Helbing, D. J. Stat. Mech. P04019 (2008). 